\title{
Pusat Pemulihan Korban Tindak KeKerasan TerhadaP Perempuan Dengan Penerapan Metode Terapi Kognitif Perilaku Di JaKarta
}

\author{
Kerin Christine Oktoria, Sumaryoto, Rachmadi Nugroho \\ Program Studi Arsitektur \\ Jurusan Arsitektur Fakultas Teknik \\ Universitas Sebelas Maret Surakarta \\ Email : kcomarbun@gmail.com
}

\begin{abstract}
Violence against women often happens in various regions in Indonesia, especially in Jakarta. This is exacerbated by the lack of infrastructure that provides a wide range of facilities to handle and prevent acts of violence. This phenomenon needs a recovery center that can accommodate a series of processes to return the original condition of the victims that include therapeutic activities, restoration of social interaction between individuals, training of various skills, as well as provide education and information related to violence and its prevention, is needed. The problem is how to design the site, space, material and color, composition and layout of the building, and landscaping at the recovery center that can support the sustainability of recovery process through the application of methods of Cognitive Behavioral Therapy. The method used is based on the architectural design characteristics obtained from the application of Cognitive Behavioral Therapy methods in object design. The result obtained is the design of a recovery center for victims of violence against women, ranging from the treatment, education and development, and housing that reflects the application of Cognitive Behavioral Therapy method as a method of recovery.
\end{abstract}

Keywords: Acts of Violence, Women, Psychology Aspect, Cognitive Behavioral Therapy

\section{PENDAHULUAN}

Tindak kekerasan terhadap perempuan semakin marak terjadi di berbagai daerah di Indonesia. Kondisi perempuan yang umumnya lebih lemah dibanding kaum pria kerap dijadikan peluang untuk bertindak semena-mena. Komnas Perempuan mencatat 119.107 kasus terjadi pada tahun 2011, 216.156 kasus pada tahun 2012, dan 279.760 kasus pada 2013, di mana jenis kekerasan yang paling banyak terjadi adalah KDRT dan kekerasan seksual. Berdasarkan data ini, terlihat jelas kondisi perempuan dalam kehidupan bermasyarakat sangat memprihatinkan. Jumlah ini terus meningkat karena korban tidak mengerti bahwa dirinya telah menjadi korban, dan sulit mempercayai orang lain sehingga memilih untuk merahasiakan peristiwa tersebut. Korban juga cenderung takut melaporkan karena merasa terancam akan konsekuensi yang lebih buruk, sehingga korban sering menyalahkan diri sendiri akan peristiwa tersebut. Minimnya pengetahuan masyarakat akan hukum yang berlaku dan langkah yang perlu ditempuh untuk mencegah dan menangani dampak tindak kekerasan memperburuk keadaaan.

Upaya menangani dan mencegah fenomena tindak kekerasan ini perlu dilakukan secara langsung pada titik permasalahan. Lokasi dengan tindak kekerasan paling tinggi menjadi sasaran utama, yaitu DKI Jakarta. Jakarta yang merupakan Ibukota Negara Indonesia berperan sebagai pusat kegiatan masyarakat, sehingga persaingan ketat dalam memperoleh pekerjaan dan tingginya biaya hidup tidak terelakkan. Hal ini menimbulkan berbagai dampak negatif terhadap kehidupan sosial masyarakat. Fakta ini didukung oleh data dari Pusat Pelayanan Terpadu Pemberdayaan Perempuan dan Anak (P2TP2A) DKI Jakarta, di mana terdapat 1.381 korban pada 
tahun 2011 dan 1.429 korban pada tahun 2012, dengan KDRT sebagai jenis kekerasan yang paling sering terjadi.

Pasca terjadinya tindak kekerasan terhadap perempuan akan muncul dampak yang diderita korban. Dampak yang terjadi tidak hanya pada aspek fisik, namun terlebih pada aspek psikis korban. Dampak psikologis ini lebih sulit dipulihkan, karena menimbulkan respon yang variatif dan cenderung destruktif. Dampak ini juga tidak kasat mata sehingga sulit untuk dideteksi. Korban memerlukan sebuah wadah yang menyediakan proses pemulihan aspek psikologis secara terstruktur dan terarah sehingga berlangsung secara efisien.

Untuk memperoleh pemulihan yang efisien, diperlukan sebuah metode terapi yang spesifik. Berdasarkan dampak yang ditimbulkan tindak kekerasan, metode Terapi Kognitif Perilaku merupakan metode terapi yang tepat diaplikasikan pada proses pemulihan. Aspek fundamental dari metode ini adalah mengonfrontrasi ketakutan masa lalu, di mana ketika menghindar dari ingatan/kenangan traumatis dapat berujung pada stagnasi kondisi psikologis (Wills \& Sanders, 2012).

\section{METODE}

Metode yang digunakan dalam memperoleh rancangan pusat pemulihan korban tindak kekerasan terhadap perempuan ditentukan berdasarkan penerapan metode Terapi Kognitif Perilaku pada objek rancang bangun. Prinsip-prinsip dari Terapi Kognitif Perilaku diterjemahkan ke dalam karakteristik pusat pemulihan yang akan menjadi kriteria dalam proses rancang bangun. Kriteria - kriteria ini akan disusun menjadi sebuah konsep perencanaan, yang diaplikasikan ke dalam konsep perancangan pusat pemulihan korban tindak kekerasan terhadap perempuan.

Perencanaan pusat pemulihan difokuskan pada pengembalian kondisi semula psikologis korban yang terganggu akibat tindak kekerasan yang dialami. Hal ini diwujudkan tidak hanya melalui proses terapi, namun dimulai dari pendekatan awal hingga pembekalan keterampilan kepada korban untuk siap kembali menjalani perannya sebagai masyarakat.

\subsection{Prinsip Metode Terapi Kognitif Perilaku}

Proses pemulihan yang akan dijalani adalah mengidentifikasi dan mengonfrontasi pikiran-pikiran irasional yang muncul akibat ketakutan terhadap masa lalu, kemudian menemukan solusi yang tepat. Proses ini didasarkan pada asumsi bahwa proses berpikir dan respon perilaku saling mempengaruhi satu sama lain. Beberapa aspek yang perlu diperhatikan dalam penerapan metode Terapi Kognitif Perilaku adalah:

a. Konseptualisasi setiap individu berbeda sesuai latar belakang dan masalah yang dihadapi, sehingga pusat pemulihan harus dapat mewadahi setiap kebutuhan

b. Dasar pemikiran terapi ini adalah hubungan yang dekat, dinamis, dan seimbang antara pengalaman individu dengan hubungannya dengan orang lain dapat mempengaruhi kondisi psikologis seseorang

c. Pasien berada dalam kondisi sulit membuka diri dan memulai hubungan dengan orang lain, sehingga dibutuhkan situasi yang kondusif; hangat, empati, peduli, sehingga pasien merasa rileks dan dapat bekerja sama dengan terapis

d. Dibutuhkan kolaborasi dan partisipasi aktif dari pasien pada proses terapi

\subsection{Karakteristik dan Kriteria Pusat Pemulihan}

Sebagai wadah kegiatan pemulihan korban tindak kekerasan dengan penerapan metode Terapi Kognitif Perilaku, terdapat berbagai karakteristik untuk menciptakan lingkungan yang mendukung proses pemulihan. Karakteristik ini akan memunculkan berbagai kondisi pusat pemulihan yang ideal dalam mewadahi proses pemulihan. Pada perkembangannya, kondisi ini akan diterjemahkan sebagai kriteria perancangan (lihat Gambar 1). Kriteria yang muncul akan diaplikasikan pada aspek rancang bangun sebagai berikut. 
a. Keseimbangan yang mencakup skala dan proporsi diwujudkan melalui ruang, gubahan dan tata bangunan yang menggunakan skala manusia dan proporsional sehingga menciptakan kondisi ramah, familiar, kondusif.

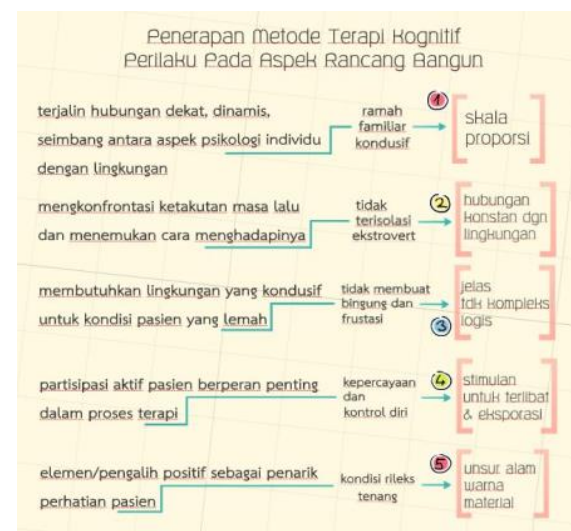

Gambar 1. Kriteria Perancangan

b. Kondisi ekstrovert diterjemahkan sebagai lokasi tapak yang tidak terisolasi di mana terdapat hubungan konstan dengan lingkungan. Hal ini diwujudkan melalui peruangan dan lansekap yang dapat memberikan pemandangan alam dan efek positif terhadap kondisi psikologis pasien.

c. Pengolahan tapak, bentuk, tata, dan tampilan bangunan harus jelas, rasional, dan familiar. Desain lansekap juga harus jelas dan aman.

d. Lingkungan dapat menjadi stimulan yang memberi kesempatan pasien untuk terlibat dan bereksplorasi, sehingga memotivasi diri untuk aktif (Velarde, 2007). Desain peruangan dan lansekap harus memberikan berbagai pilihan bagi pasien melalui organisasi ruang, pengaturan sirkulasi dan perabot yang digunakan.

e. Keberadaan unsur alam dapat berupa vegetasi dan air pada tapak, ruang, dan lansekap. Warna dan material juga dapat menjadi pengalih positif melalui kombinasi warna dan tekstur.

\section{ANALISIS}

\subsection{Analisis Peruangan}

Analisis kebutuhan dan luasan ruang diperoleh berdasarkan pelaku, jenis dan karakter kegiatan, serta kebutuhan ruang gerak dalam menunjang kenyamanan (lihat Tabel 1).

Tabel 1.Kebutuhan Ruang

\begin{tabular}{|l|l|}
\hline \multirow{2}{*}{ KEGIATAN } & \multicolumn{1}{|c|}{ PERUANGAN } \\
\hline Terapi & R. Terapi \\
\cline { 2 - 2 } & R. Konseling \\
\cline { 2 - 2 } & R. Periksa \\
\hline \multirow{4}{*}{ Hunian } & K. Tidur \\
\cline { 2 - 2 } & KM \\
\cline { 2 - 2 } Pendidikan \& & Dapur \\
\cline { 2 - 2 } & R. Bersama \\
\hline Penbangan & R. Kelas \\
\cline { 2 - 2 } & R. Workshop \\
\cline { 2 - 2 } & Perpustakaan \\
\hline Workshop & R. Pamer \\
\cline { 2 - 2 } & R. Seminar \\
\cline { 2 - 2 } & Aula \\
\hline
\end{tabular}

Berdasarkan kebutuhan ruang yang ada, diperoleh total luas ruang yang dibutuhkan berdasarkan kelompok kegiatan, yaitu:
a. Kegiatan terapi : $396.48 \mathrm{~m}^{2}$
b. Kegiatan hunian : $1321.68 \mathrm{~m}^{2}$
c. Kegiatan pendidikan \& pengembangan : $377.64 \mathrm{~m}^{2}$
d. Kegiatan workshop : $312.54 \mathrm{~m}^{2}$
e. Kegiatan pengelola : $423.66 \mathrm{~m}^{2}$
f. Kegiatan servis : $169.18 \mathrm{~m}^{2}$

\subsection{Analisis Pemilihan Lokasi}

Kriteria pemilihan lokasi adalah:

a. Tidak terisolasi dari lingkungan, komunitas, dan arsitektur lainnya

b. Jauh dari lingkungan negatif dan bising

c. Lingkungan aksesibel dan aman

d. Keberadaan unsur alam

Lokasi terpilih berada pada Jalan Bumi Cengkareng Indah, Jakarta Barat. Dengan luas $\pm 15.000 \mathrm{~m}^{2}$, tapak berbatasan dengan pemukiman penduduk pada sisi timur dan selatan, Universitas Satyagama pada sisi barat, dan Jalan Bumi Cengkareng Indah pada sisi utara (lihat Gambar 2). 


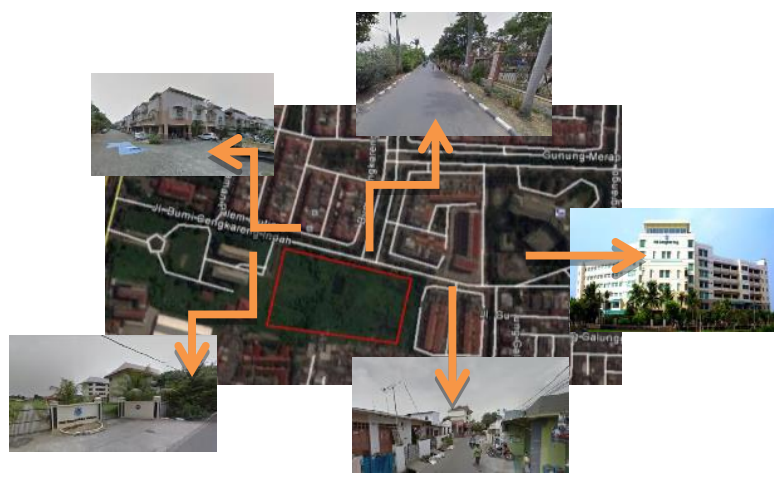

Gambar 2. Tapak Terpilih

\subsection{Analisis Pengolahan Tapak}

Aspek pertama yang dianalisis adalah sinar matahari dan pembayangannya pada tapak. Analisis ini dibutuhkan sebagai dasar pertimbangan dalam tata ruang dan bangunan, serta pemilihan material. Sinar matahari menjadi faktor utama dalam sistem pencahayaan alami pusat pemulihan.

Aspek kedua yang dianalisis adalah kebisingan, karena pusat pemulihan membutuhkan lingkungan yang tenang dan kondusif (lihat Gambar 3).

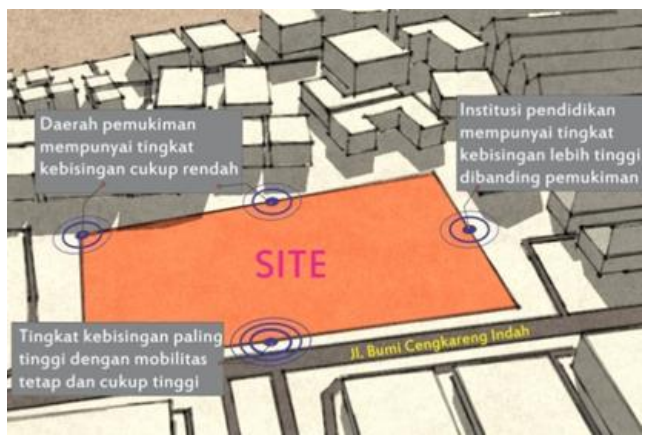

Gambar 3. Analisis Kebisingan

Aspek ketiga yang dianalisis adalah pencapaian bangunan. Konsep aksesibel dan familiar harus dapat ditunjukkan mulai dari proses pencapaian bangunan yang dialami oleh calon pasien/korban. Hal ini berdampak pada kondisi psikologis sehingga calon pasien stabil dan tenang. Proses pencapaian bangunan pusat pemulihan berbentuk langsung, di mana pintu masuk dan bangunan terlihat dengan jelas. ME dan SE juga ditentukan berdasarkan proses pencapaian yang ada (lihat Gambar 4).

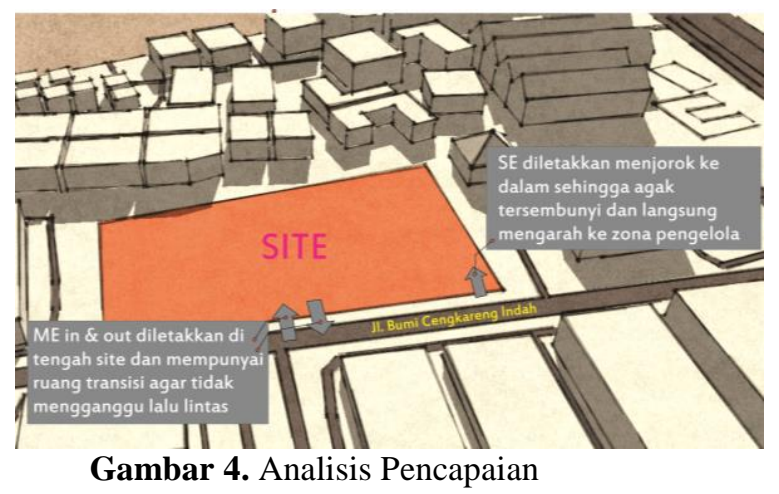

Aspek keempat yang dianalisis adalah pemintakatan. Analisis ini dilakukan berdasarkan jenis kegiatan yang diwadahi dengan pertimbangan faktor penyinaran sinar matahari dan tingkat kebisingan. Mintakat terapi sebagai pusat kegiatan harus aksesibel dari berbagai mintakat lainnya, dan terletak pada sisi dengan kebisingan rendah. Mintakat hunian harus mempunyai akses ke mintakat terapi dan pendidikan dan pengembangan, dengan kebutuhan intensitas matahari yang cukup tinggi (lihat Gambar 5).

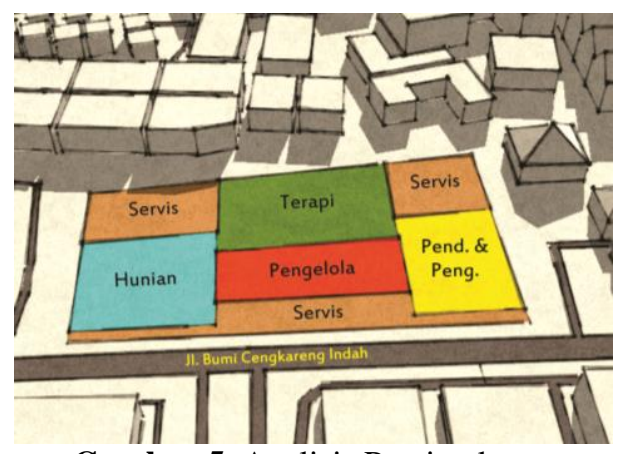

Gambar 5. Analisis Pemintakatan

\subsection{Analisis Peruangan}

Kriteria dalam menentukan peruangan adalah:
a. Hubungan dekat, dinamis, dan seimbang antara ruang yang ada
b. Organisasi ruang dan sirkulasi jelas dan logis, tidak kompleks, tersusun dengan baik dan mudah digunakan
c. Terdapat hubungan konstan dengan lingkungan
d. Bentuk ruang jelas dan rasional 
e. Terdapat elemen/pengalih positif

f. Karakteristik pengguna

Proporsi dan skala menjadi inti dari penentuan dimensi ruang agar tidak monumental maupun sempit. Organisasi ruang dan sirkulasi yang tercipta harus jelas dan nyaman agar tidak membuat pasien bingung dan frustasi. Ruang-ruang dengan karakteristik pengguna yang sama perlu dikelompokkan untuk mempermudah akses dan meminimalisasi penggunaan koridor.

\subsection{Analisis Penggunaan Warna dan Material}

Kriteria penggunaan warna adalah:

a. Hubungan dinamis dan seimbang dalam ruangan

b. Menciptakan lingkungan yang aktif

c. Sebagai elemen/pengalih positif dalam ruangan

Penggunaan warna monokrom memberikan rasa tenang, damai, dan menurunkan rasa gugup sehingga cocok digunakan pada ruang terapi (lihat Gambar 6).

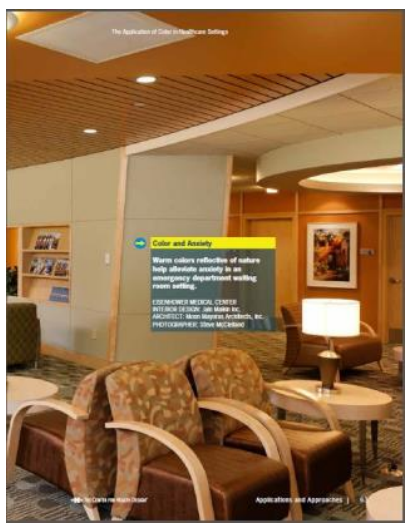

Gambar 6. Kombinasi Warna Monokrom

Sebaliknya, penggunaan kombinasi beberapa warna dengan sifat yang berbeda (hangat dan dingin) dapat memunculkan kesan dinamis, sehingga menciptakan lingkungan aktif yang mendorong pasien untuk terlibat dan bersosialisasi. Kombinasi ini diaplikasikan pada ruang pendidikan dan pengembangan (lihat Gambar 7).

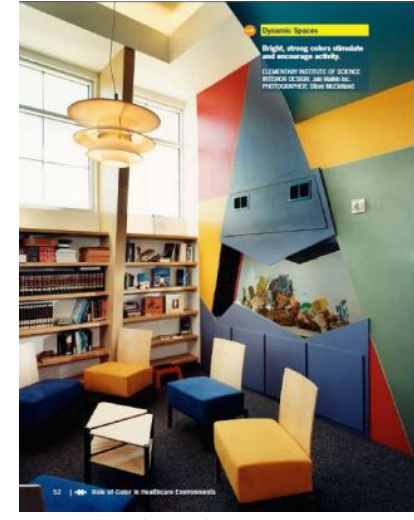

Gambar 7. Kombinasi Warna Hangat

Kriteria penggunan material adalah:

- Penggunaan material lokal

- Meminimalisasi penggunaan material sintetis

Material lokal seperti kayu dan batu bata dapat memberikan kesan lembut dan hangat yang dapat menenangkan pasien dan mendukung proses pemulihan. Kombinasi material lokal dengan elemen alam juga semakin memberikan kesan tenang dan lembut. Penggunaan material prefabrikasi dilakukan seminimal mungkin karena memberikan kesan kaku, asing, dan keras. Selain itu, penggunaan material ini dapat mengganggu kesehatan pengguna bangunan. Material ini tetap digunakan sebagai penyeimbang material lokal agar tidak terkesan monoton.

\subsection{Analisis Gubahan dan Tata Bangunan}

Kriteria gubahan dan tata bangunan adalah:

a. Bentuk dan komponen pendukung bangunan jelas, logis, tidak kompleks, tersusun dengan baik, namun tetap seimbang dan dinamis

b. Tata bangunan dapat dikenali dengan mudah, aksesibel, dan memberikan rasa aman.

Bentuk lingkaran dan persegi mempunyai karakter yang tepat untuk pusat pemulihan yang direncanakan. Secara umum, korban memerlukan ruang yang ramah, tidak terlalu luas maupun sempit, tidak terlalu kaku maupun dinamis. Bentuk tidak umum dengan sudut 
lancip harus dihindari karena memberikan kesan asing dan menakutkan. Persegi yang rasional dan netral dengan efisiensi ruangan yang tinggi dapat mewadahi sebagian besar kegiatan, sedangkan unsur lingkaran dibutuhkan untuk memberikan kedinamisan bentuk dan terpusat. Lingkaran juga dapat menjadi suatu aksen bentuk dan menarik perhatian pengguna pada points of interest bangunan. Gubahan bangunan yang direncanakan merupakan gabungan dari bentuk lingkaran dan persegi.

Tata bangunan yang dapat mengakomodasi kebutuhan pusat pemulihan yang direncanakan adalah pola radial. Radial dipilih sebagai pola kegiatan karena tetap ingin memberikan kesan ekstrovert terhadap lingkungan, dimana hal terebut merupakan salah satu tujuan metode terapi. Selain itu, pola radial dapat memunculkan kesan dinamis/pergerakan dalam sistem tata bangunan pusat pemulihan (lihat Gambar 8).

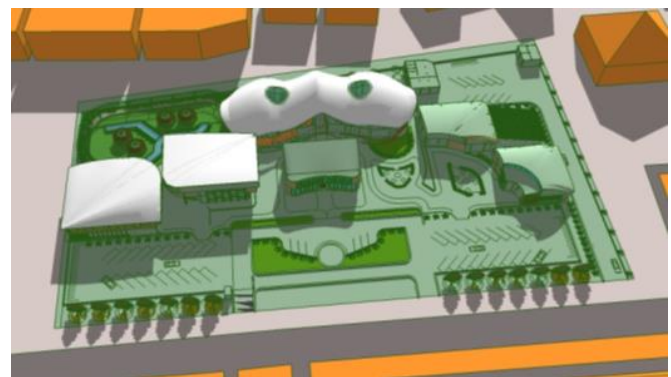

Gambar 8. Gubahan dan Tata Bangunan

\subsection{Analisis Tampilan Bangunan}

Kriteria tampilan bangunan adalah:

a. Bentuk jelas, hindari bentuk yang tidak umum dan sudut lancip

b. Terdapat elemen pelindung (barrier) terhadap sinar matahari, angin, dan kebisingan.

Tampilan bangunan menghindari bentuk - bentuk yang asing sehingga menghambat proses pemulihan. Kesan ramah, familiar, dan aman merupakan fokus dari desain, dimana tampilan ini berperan sebagai lapisan paling luar dari sebuah bangunan yang menjadi identitas dari sebuah bangunan. Selain dari aspek psikologis, kulit bangunan menjadi salah satu penghalang berbagai dampak unsur alam, terutama karena bangunan berada pada lingkungan tropis. Desain kulit bangunan tetap harus memperhatikan arah matahari dan angin, serta dampaknya terhadap kondisi di dalam bangunan.

\subsection{Analisis Lansekap}

Kriteria lansekap adalah:

a. Desain aksesibel, familiar, aman

b. Desain memberikan kesempatan pasien untuk terlibat dan menentukan apa yang akan dilakukannya

c. Keberadaan unsur-unsur alam sebagai elemen positif

d. Terdapat hubungan konstan antara ruang luar dan dalam

Desain lansekap pusat pemulihan yang direncanakan harus jelas dan mudah dimengerti, untuk memberikan rasa aman dan nyaman kepada pasien. Rasa nyaman juga dapat diwujudkan melalui adanya hubungan ruang luar dan dalam pada pusat pemulihan. Kepercayaan diri dan keinginan untuk berperan aktif pasien muncul dari adanya kemampuan mengontrol. Hal ini dapat diwujudkan dari pengaturan perabot lansekap. Lansekap yang dapat memberikan dampak positif terhadap kondisi psikologis pasien adalah lansekap alami, yang terdiri dari unsur unsur penyusun alami seperti vegetasi. Vegetasi harus dipilih dan ditata dengan baik agar dapat memberikan efek positif terhadap proses pemulihan yang diwadahi (lihat Gambar 9).

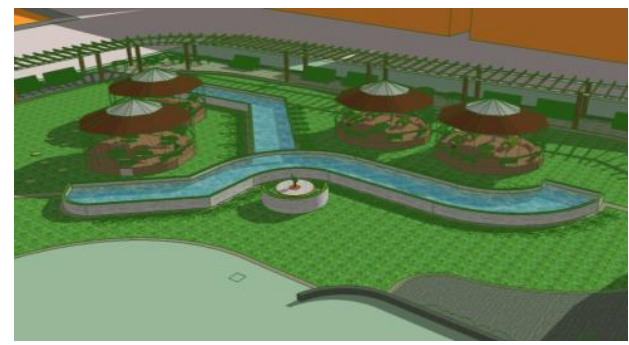

Gambar 9. Desain Taman Terapi

\section{KESIMPULAN (KONSEP DESAIN)}

Pusat pemulihan korban tindak kekerasan terhadap perempuan di Jakarta adalah suatu fasilitas untuk mewadahi rangkaian proses pengembalian aspek psikologis korban pasca tindak kekerasan ke 
kondisi semula, dimana proses ini mencakup kegiatan terapi sebagai kegiatan utama, penyediaan rumah aman (shelter), pendidikan dan pengembangan keterampilan, hingga korban siap untuk kembali dan menjalani perannya di kehidupan masyarakat luas.

Konsep perancangan diwujudkan dari penerapan metode Terapi Kognitif Perilaku sehingga muncul karakteristik dan kriteria yang perlu dipenuhi untuk merancang pusat pemulihan yang tepat (lihat Gambar 10). Organisasi ruang jelas, tidak kompleks, tersusun dengan baik, dan skalatis. Penggunaan warna dan material memberikan berbagai kesan secara psikologis yang diaplikasikan sesuai fungsi ruangan (lihat Gambar 6 dan 7). Bentuk dasar yang digunakan adalah gabungan antara persegi dan lingkaran, dengan tata bangunan menggunakan pola radial (lihat Gambar 8). Tampilan bangunan mempunyai konsep hampir sama dengan gubahan bangunan, didominasi bentuk persegi dan lingkaran. Konsep lansekap diwujudkan pada taman terapi sebagai inti desain lansekap (lihat Gambar 9). Jalur sirkulasi, tata vegetasi dan perabot lansekap didesain secara jelas dan mudah dimengerti agar memberikan rasa aman dan nyaman.

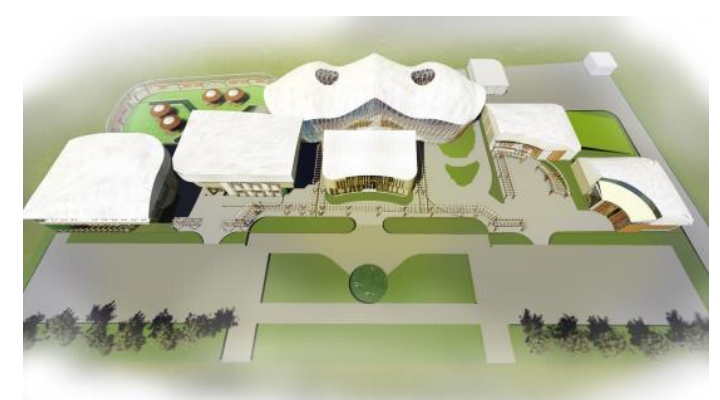

Gambar 10. Eksterior Bangunan

\section{REFERENSI}

Velarde, M. D., Fry, G., Tveit, M. 2007. Health Effects of Viewing Landscapes:

Landscape Types in Environmental

Psychology. Elsevier GmbH.

Wills, Frank \& Sanders, Diana. 2012.

Cognitive Behaviour Therapy:

Foundations for Practice. London:

SAGE. 